\title{
HBs Antigen ELISA as a Marker for Blood Transfusion Safety and Antenatal Screening: Is It Enough?
}

\author{
Gupta Sangita, Verma Devki*, Gupta Sandhya, Karmakar Jayanta and Singhal Sanjay
}

Department of Microbiology, ESIC PGIMSR, Basaidarapur, New Delhi, India

*Corresponding author

Keywords

HBs antigen,

ELISA,

Transfusion,

Antenatal screening

Article Info

Accepted:

07 December 2018

Available Online:

10 January 2019

\section{A B S T R A C T}

Hepatitis B virus (HBV) infection is a serious global health problem affecting two billion people worldwide, and 400 million people suffer from chronic HBV infection. In India Hepatitis B surface antigen ( $\mathrm{HBsAg}$ ) is used as the sole marker to check safety of blood transfusion as well as antenatal screening of mothers to prevent transmission of infection to newborn. Despite mandatory screening for HBsAg by Enzyme Linked Immuno Sorbent Assay (ELISA) or similar tests, transfusion-associated HBV (TAHBV) continues to be a major problem in India, more so in patients receiving repeated transfusions. Present study was undertaken to detect the presence of occult hepatitis B (OBI) infections in normal healthy adult population which go undetected by routine HBsAg screen and to ascertain whether HBsAg test alone is enough as a screening test to prevent hepatitis transmission to recipient after blood transfusion and to newborn from infected mother. A total of 1421 serum samples collected from HBsAg-negative healthy adults (18 to 50 years of age) were tested for the presence of antibodies to hepatitis B core antigen (anti- $\mathrm{HBc}$ ). All samples reactive for anti-HBc antibody were then investigated for presence of anti-HBs. Anti-HBc positive samples with antibodies to $\mathrm{HBs}$ antigen (anti-HBs) titres $<10 \mathrm{mIU} / \mathrm{mL}$ were considered potentially infectious for HBV. Out of 1421 samples tested, $163(11.5 \%)$ blood samples were found to be reactive for anti-HBc. 58 out of these $163(35.6 \%)$ samples were non-reactive for anti-HBs $(<10 \mathrm{mIU} / \mathrm{mL})$. Overall $4.1 \%$ of $\mathrm{HBsAg}$ negative blood was found to be potentially infectious for transmitting HBV. The positivity rate of Occult hepatitis infection was double in males $(6.81 \%)$ as compared to females $(3.81 \%)$. Keeping in view high rate of occult hepatitis infection in HBs antigen negative blood, we suggest routine anti-HBc screening of blood with anti-HBc and further testing of anti-HBc positive blood either for anti-HBs or HBV DNA to ensure safety of blood transfusion and prevent perinatal transmission to newborn.

\section{Introduction}

Hepatitis B virus is one of the most common infectious diseases worldwide and is a serious global health problem affecting close to two billion people worldwide (1). There are approximately 400 million chronic hepatitis B carriers around the world (2), of which more than 40 million are from India alone (3). Various serum antigens and antibodies can be tested to detect acute, chronic or occult hepatitis B infections. HBs antigen is the first 
serum marker to appear after infection and persists throughout the clinical illness except during window period when seroconversion to anti-HBs just begins. IgM and anti-HBc antibodies also appear in the acute phase of infection but somewhat after HBs antigen and $\mathrm{HBe}$ antigens. IgM and anti-HBc switch to IgG type during the course of disease and persist for an indefinite time after virus clearance. However these are non neutralizing antibodies and are not related to recovery from hepatitis. It is the presence of antibodies against HBsAg (anti-HBs) which are a marker of recovery and immunity. Anti-HBc coexisting with anti-HBs usually indicates a previous HBV infection, and when it coexists with HBsAg, a current infection, either acute or chronic (4). Total anti-HBc is also the only serum marker to give positive result during window period and in patients with occult hepatitis B infection. OBI is defined as the presence of HBV DNA in blood or tissues without detectable $\mathrm{HBs} A g$, with or without antibody to hepatitis B core antigen or hepatitis B surface antigen (5). A positive OBI test may be detected in various clinical conditions, including: (1) the incubation period of acute infections; (2) the tail-end stage of chronic hepatitis B; (3) low-level viral replication after recovery from hepatitis; and (4) escape mutants not detected by current HBsAg tests.

Transfusion-associated HBV continues to be a major problem in India, more so in patients receiving repeated transfusions (6). The incidence of TAHBV in patients receiving multiple transfusions, such as thalassemia, ranged from $17.9 \%$ in the first year to $69.2 \%$ by the third year (6).Presently, screening for HBsAg is the only mandatory screening test for the detection of Hepatitis B virus (HBV) infection in blood banks in India as per the Drugs and Cosmetics Act, 1940 and the amendments thereof Screening of blood for the detection of HBsAg, however, does not rule out the risk of transmission of hepatitis B totally, because during the serological response of the host to infection, there are phases during which the HBsAg cannot be detected in the blood, although hepatitis B infection is present. Similarly, during these phases HBsAg negative mothers can also transmit Hepatitis B to their fetus.

Our study has been conducted to estimate the magnitude of hepatitis $B$ infections which go undetected by routine $\mathrm{HBsAg}$ screen in normal healthy adult population by using anti$\mathrm{HBc}$ ELISA so as to ascertain whether HBsAg test alone is enough as a screening test to prevent hepatitis transmission to recipient after blood transfusion and to newborn from infected mother.

\section{Materials and Methods}

This study was conducted by the Department of Microbiology, PGIMSR Basaidarapur, New Delhi, India from September 2017- February 2018. HBsAg negative serum samples that were collected from healthy asymptomatic (for hepatitis) adults in the age group of 18 to 50 years were included in our study. These samples were obtained by lab for routine HBsAg screening during antenatal period or before any surgery as a part of routine hospital protocol. All these samples were screened for HBsAg by ELISA (Monolisa HBsAg ULTRA, Biorad). Out of these, HBsAg negative samples were tested for the presence of total anti-HBcby ELISA (Monolisa Anti-HBc Plus, Biorad). Samples that were reactive for anti$\mathrm{HBc}$ were then tested for anti-HBs titres by ELISA (Monolisa Anti-HBs Plus, Biorad). Samples with anti-HBs level $<10$ mIU per milliliter were considered nonreactive. For better understanding, the anti-HBs reactive samples were stratified into two groups i.e., 10-100 mIU per milliliter (low level) and > $100 \mathrm{mIU}$ per milliliter (high level). Based on above test results, those $\mathrm{HBsAg}$ negative 
patients who were tested reactive for total anti-HBc but had anti-HBs titres $<10 \mathrm{mIU} / \mathrm{mL}$ (anti-HBc alone positive) were considered as having occult hepatitis B infection.

\section{Results and Discussion}

A total of 1421 HBsAg negative serum samples were selected over a period of six months (September 2017 to February 2018). All the patients were between 18 to 50 years of age. Out of these 1069 (75.2\%) were females and $352(24.8 \%)$ were males. These were then tested for the presence of total anti$\mathrm{HBc}$ (Fig. 1). Out of these $1421 \mathrm{HBsAg}$ negative samples, $11.5 \%$ (163/1421) tested reactive for total anti-HBc. Anti-HBc positivity was higher among males $(15.9 \%)$ as compared to females (10\%).The samples reactive for anti-HBc were further tested for the presence of anti-HBs. Out of these $35.6 \%$ (58/163) were found nonreactive for anti-HBs with levels $<10 \mathrm{mIU} / \mathrm{mL}$. These were labelled as anti-HBc only positive samples. Another $24.6 \%$ (40/163) were low level reactive and $39.8 \%$ (65/163) were high level reactive (Table 1). Thus out of total 1421 patients included in our study, $58(4.1 \%)$ were found to be anti-HBc only positive samples (HBsAg negative, total anti-HBc reactive and anti-HBs nonreactive). These patients are probable occult hepatitis $\mathrm{B}$ positive and have the potential to transmit HBV infections. Overall anti-HBc only positivity was also seen more among males than females $(6.81 \% \mathrm{v} / \mathrm{s} 3.81 \%)$ (Table 2).

Over the past few decades, after the introduction of reliable serologic screening of blood donations, post transfusion hepatitis has become rare. However, the identification of blood donors with occult HBV infection (donors who are negative for HBsAg but have detectable circulating HBV DNA) has led to some concern with regard to the safety of blood supply (7). It is generally accepted that the diagnosis of infection by HBV is based on the presence of the HBsAg in the bloodstream (8). However, screening of blood donors for HBsAg does not totally eliminate the risk of HBV infection through blood transfusion (9). Since the absence of this marker in the serum does not completely exclude the presence of HBV DNA (10). It is possible that, donors with occult HBV infection, who lacked detectable HBsAg but were positive for antiHBcand/or HBV DNA, maybe harboring HBV infection and thus are a potential source of HBV infection (11).

The prevalence of OBI varies greatly among different countries of the world. It largely depends on the prevalence of Hepatitis B in that country. The various countries have been divided into three groups (high, intermediate and low) according to HBV endemicity. India falls in the intermediate endemicity zone (prevalence of $2-7 \%$, with an average of $4 \%$ ), with a disease burden of about 50 million (12). The prevalence of OBI varies even within India and is higher in the high risk groups like those with HIV, alcoholic cirrhosis and tribals (12).

Our study was aimed at calculating the prevalence of probable OBI in the general healthy population. In our study $11.5 \%$ (163/1421) of HBsAg negative patients were found to be anti-HBc positive. This is similar to other studies done by Dhawan et al., (13) and Makroo et al., (14) which revealed the prevalence of anti-HBc to be $8.4 \%$ and $9.19 \%$ respectively. However similar study conducted by Asim et al., in New Delhi showed higher anti-HBc positivity of $18.9 \%$. (15) This variation in positivity could be due to the difference in patient profiles. Out of these anti-HBc positive patients, $35.6 \%$ $(58 / 163)$ were anti-HBs nonreactive. This is similar to study by Asim et al., (15) which had anti-HBc only rate of $37 \%$ but lower than Dhawan et al., which had anti-HBc only rate of $49.3 \%$. 
Table.1 Anti-HBs titres in anti-HBc reactive samples

\begin{tabular}{|l|c|c|}
\hline $\begin{array}{l}\text { Anti-HBs titre } \\
\text { (mIU/ milliliter) }\end{array}$ & $\begin{array}{c}\text { Percentage of anti-HBc } \\
\text { reactive samples } \\
(\mathbf{n}-=\mathbf{1 6 3})\end{array}$ & $\begin{array}{c}\text { Percentage } \\
\text { of total serum samples } \\
(\mathbf{n = 1 4 2 1})\end{array}$ \\
\hline$<10$ & $35.6 \%(58)$ & $4.1 \%$ \\
\hline $10-99$ & $24.6 \%(40)$ & $2.8 \%$ \\
\hline$\geq 100$ & $39.8 \%(65)$ & $4.6 \%$ \\
\hline
\end{tabular}

Table.2 Gender wise distribution of study population

\begin{tabular}{|l|l|l|}
\hline & Females & Males \\
\hline Healthy patients tested & $1069(75.2 \%)$ & $352(24.8 \%)$ \\
\hline Anti-HBc reactive & $10 \%(107 / 1069)$ & $15.9 \%(56 / 352)$ \\
\hline Anti-HBc only positive & $3.81 \%(34 / 1069)$ & $6.81 \%(24 / 352)$ \\
\hline
\end{tabular}

Fig.1

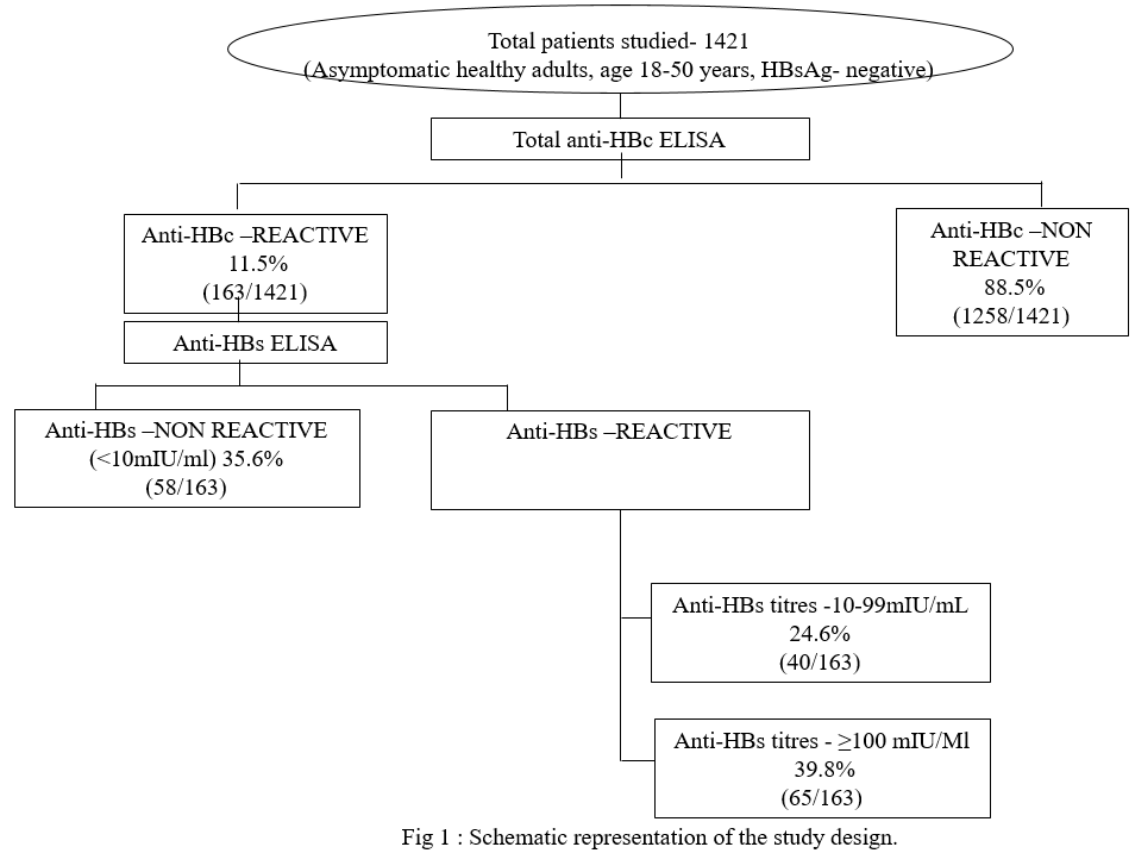

Overall in our study 4.1\% (58/1421) patients had anti-HBc antibodies in their blood in absence of HBsAg or anti-HBs thus making them potentially infectious for transmitting hepatitis B infection.

In other studies by Dhawan and Asim et al., this rate was $4.1 \%$ and $7.03 \%$ respectively. $(13,15)$ Asim et al., performed HBV DNA testing of all anti-HBc positive samples. They found HBV DNA positivity to be $12.4 \%$ in anti-HBc alone positive group as compared to $4.6 \%$ in both anti-HBc and anti-HBs positive group. This indicates that even the mere presence of anti-HBs does not rule presence of HBV DNA in the patient's serum completely although such chances are rare. 
In conclusion, transfusion transmitted hepatitis is a life threatening public health problem worldwide. In developing countries like ours only HBsAg is done to rule out Hepatitis B virus infections. Thus individuals with OBI get missed hence posing a risk for transmission of Hepatitis B through blood transfusion. Similarly, HBsAg is the only serum marker tested for prevention of perinatal hepatitis transmission from mother to fetus. OBI is also an important risk factor for developing cirrohosis and hepatocellular carcinoma in patients.

Our study highlights the presence of such infections which are missed by routine HBsAg screen alone. However, in developing countries like ours, neither all samples can be tested for HBV DNA nor all anti-HBc positive units $(11.5 \%$ in our study) can be discarded. Thus an alternative testing strategy should be chalked out. This could be testing for anti-HBc followed by anti-HBs or testing anti-HBc and then HBV DNA for anti-HBc reactive samples.

\section{References}

1. Schmidt M, Nubling CM, Scheiblauer $H$, Chudy M, Walch LA, Seifried E, Roth WK, Hourfar MK. Anti-HBc screening of blood donors: a comparison of nine anti-HBc tests. Vox Sang 2006; 91: 23743.

2. WHO. Global hepatitis report 2017. Geneva: World Health Organization, 2017

3. Tandon BN, Acharya SK, Tandon A (1996) Epidemiology of hepatitis B virus infection in India. Gut 38: S56-S59.

4. Gitlin N. Hepatitis B: diagnosis, prevention, and treatment. ClinChem 1997; 43: 1500-6.

5. Bhatti FA, Ullah Z, Salamat N, Ayub M, Ghani E. Anti hepatits B core antigen testing, viral markers, and occult hepatitis $\mathrm{B}$ virus infection in Pakistani blood donors: implications for transfusion practice. Transfusion 2007;47:74-9.

6. Chaudhuri V, Nanu A, Panda SK, Chand P. Evaluation of serologic screening of blood donors in India reveals a lack of correlation between anti-HBc titer and PCR-amplified HBV DNA. Transfusion. 2003;43:1442-8.

7. Yotsuyanagi H, Yasuda K, Moriya K, Shintani Y, Fujie H, Tsutsumi T, et al.,. Frequent presence of $\mathrm{HBV}$ in the sera of HBsAg-negative, anti-HBc-positive blood donors. Transfusion 2001; 41 : 1093-9.

8. Badur S, Akgun A. Diagnosis of hepatitis B infections and monitoring of treatment. J ClinVirol 2001; 21:229-37.

9. Conjeevaram HS, Lok AS. Occult hepatitis B virus infection: a hidden menace? Hepatology 2001; 34:204-6.

10. Comanor L, Holland P. Hepatitis B virus blood screening: unfinished agendas. Vox Sang 2006;91: 1-12.

11. Dreier J, Kroger M, Diekmann J, Gotting C, Kleesiek K. Low- level viraemia of hepatitis $\mathrm{B}$ virus in an anti-HBc- and antiHBs-positive blood donor. Transfus Med 2004;14:97-103.

12. Ray G. Current Scenario of Hepatitis B and Its Treatment in India. $\mathbf{J}$ ClinTranslHepatol. 2017 Sep 28; 5(3): 277-6.

13. Dhawan HK, Marwaha N, Sharma RR, Chawla Y, Thakral B, Saluja K, Sharma SK, Thakur MK, Jain A. Anti-HBc screening in Indian blood donors: Still an unresolved issue. World J Gastroenterol 2008 Sep 14;14(34):5327-30.

14. Makroo RN, Chowdhry M, Bhatia A, Arora B,Rosamma NL. Hepatitis B core antibody testing in Indian blood donors: A double-edged sword! Asian J Transfus Sci. 2012 Jan-Jun; 6(1): 10-3. 
15. Asim M, Ali R, Khan LA, Hussain SA, Singla R, Kar P. Significance of Anti$\mathrm{HBc}$ screening of blood donors \& its association with Occult Hepatitis B Virus infection: Implications for blood transfusion. Indian J Med, Sep 2010; 132: 312-7.

\section{How to cite this article:}

Gupta Sangita, Verma Devki, Gupta Sandhya, Karmakar Jayanta and Singhal Sanjay. 2019. HBs Antigen ELISA as a Marker for Blood Transfusion Safety and Antenatal Screening: Is It Enough? Int.J.Curr.Microbiol.App.Sci. 8(01): 655-660.

doi: https://doi.org/10.20546/ijcmas.2019.801.073 